The Glasgow Mathematical Journal is the continuation of the Proceedings of the Glasgow Mathematical Association. It was founded in 1952 by the late Professor T. M. MacRobert and published with the support of the University Court of the University of Glasgow. The present name was adopted in 1967 and since 1987 the Journal has been owned by the Glasgow Mathematical Journal Trust, an independent charitable trust (Scottish Charity Number SC006017).

\title{
Editorial Policy
}

The Glasgow Mathematical Journal publishes high quality original research papers in pure and applied mathematics. Its policy is to feature a wide variety of research areas and it welcomes the submission of papers from all parts of the world. Selection for publication is on the basis of reports from specialist referees commissioned by the Subject Editors or Editor-in-Chief.

\section{Submission of Manuscripts}

The journal uses an online submission and refereeing system, EditFlow. To submit your paper, please go to: https://cup.msp.org/submit/gmj. When submitting a paper you will be asked to nominate a subject editor. The current subject editors and their areas of interest are as follows:

\section{SUBJECT EDITORS:}

\begin{tabular}{|c|c|c|c|}
\hline $\begin{array}{l}\text { Andrew Baker } \\
\text { Alex Bartel }\end{array}$ & $\begin{array}{l}\text { Algebraic Topology } \\
\text { Number Theory, Arithmetic Geometry, } \\
\text { Finite Groups }\end{array}$ & Jan Grabowski & $\begin{array}{l}\text { Noncommutative Rings and Algebras, } \\
\text { Quantum Algebra, Cluster Algebras, } \\
\text { Representation Theory }\end{array}$ \\
\hline Neal Bez & $\begin{array}{l}\text { Harmonic Analysis, Partial Differential } \\
\text { Equations, Geometric Analysis }\end{array}$ & Volodymyr Mazorchuk & $\begin{array}{l}\text { Representation Theory, Lie Algebras, } \\
\text { Semigroups, Categorification }\end{array}$ \\
\hline Gavin Brown & Algebraic Geometry & Vitaly Moroz & Applied Analysis and Nonlinear Partial \\
\hline Oleg Chalykh & $\begin{array}{l}\text { Mathematical Physics, Integrable Systems } \\
\text { and Geometry, Orthogonal Polynomials and } \\
\text { Special Functions }\end{array}$ & $\begin{array}{l}\text { Constanze Roitzheim } \\
\text { Colva M. Roney-Dougal }\end{array}$ & $\begin{array}{l}\text { Differential Equations } \\
\text { Algebraic Topology } \\
\text { Finite Group Theory, Computational Algebra, }\end{array}$ \\
\hline
\end{tabular}

You should choose a subject editor closest to your field. Alternatively you may nominate the Editor-in-Chief, Brendan Owens, who will assign a Subject Editor to deal with your submission.

During the submission process you will be asked to confirm that the paper is not being considered for publication elsewhere.

The Journal encourages the use of .pdf files. LaTeX and Postscript as well as other formats can be uploaded but these will be converted into .pdf format. Note that .dvi files cannot be converted. Care should be taken with this option, especialy if non-standard macros are being used, and the .pdf version the system produces should be carefully checked before final submission.

Upon acceptance of a paper, the author will be asked to transfer copyright to the Glasgow Mathematical Journal Trust.

\section{Layout of manuscripts}

Papers should be typed or word-processed in double spacing throughout, with wide margins and on one side of the paper. They should be prepared so as to conform to the practice in current issues of the Journal as regards general layout, references, tables and figures. Please avoid footnotes if possible. Papers must begin with an abstract of not more than 200 words, and they should list at least one AMS 2010 classification number or keyword. This information is also required before your manuscript can be uploaded. Instructions regarding unusual symbols or any typographical point that might cause confusion should be provided on a separate sheet. These may be uploaded as separate files. If special fonts are used, they should conform to the Journal's practice. Authors are reminded that they should retain a copy of anything submitted for publication since neither the Journal nor the publisher can accept liability for any loss.

\section{Illustrations}

Text figures must be suitable for direct photographic reproduction and supplied separate from the text but allocated clearly to sections of the text. Low resolution version may be uploaded at submission as separate files. Originals of figures should not be sent until the paper has been accepted. A list of captions for figures should be attached separately. Black and white figures are free for both online and print publication, while colour figures are free for online publication only. Colour figures for print publication are subjected to RightsLink charges ( $£ 200 / \$ 320$ per figure). Figures should be submitted in the Encapsulated PostScript (EPS/.eps) format; when that is not possible, Word documents containing figures and illustrations in .jpg format are also acceptable.

\section{References}

References should be placed at the end of the paper, arranged and numbered in alphabetical order of the author's names. Titles of journals should be abbreviated as in Mathematical Reviews. In the text, reference numbers should be enclosed in square brackets to distinguish them from formula numbers which should be quoted in round brackets. A reference to a book should give the author, title (in italics), edition, publisher, year of publication; e.g.

[1] P. T. Johnstone, Stone Spaces, Cambridge Studies in Advanced Math. no. 3 (Cambridge University Press, 1982).

A reference to an article should give the author, title of article, short title of periodical (in italics), series number (if any), volume number, year, and the beginning and end pages of the paper; e.g.

[2] R. Guralnick, T. Pentilla, C. E. Praeger and J. Saxl, Finite linear groups, Proc. London Math. Soc. (3) 78 (1999), $167-214$.

\section{Proofreading}

Prior to publication sets of proofs of each paper will be sent to authors. For papers with more than one author the proofs are sent to the first named author unless the Editors receive other instructions. Authors are asked to correct and return proofs promptly. Typographical or factual errors only may be changed at proof stage. The publisher reserves the right to charge authors for excessive corrections of nontypographical errors. No page charge is made.

\section{Offprints}

No paper offprints are provided, but the corresponding author will be sent the pdf of the published article. Print offprints may be purchased at extra cost at proof stage.

\section{Grants}

The Glasgow Mathematical Journal Trust Fund offers grants in support of mathematical projects and events of demonstrable benefit to mathematics in Scotland. Further details and application forms can be obtained from http://www.icms.org.uk/activities/gmjt.php.

This journal issue has been printed on FSC-certified paper and cover board. FSC is an independent, non-governmental, not-for-profit organization established to promote the responsible management of the world's forests. Please see www.fsc.org for information. 


\section{Glasgow \\ Mathematical \\ Journal}

\section{Volume 63 Part 3 September 2021}

\section{CONTENTS}

Jason Gaddis, Prime and semiprime quantum linear space smash products $\quad 503$

T. H. Lenagan and L. Rigal, Generalised quantum determinantal rings are maximal orders $\quad 515$

Jordan McMahon and Nicholas J. Williams, The combinatorics of tensor products of higher Auslander algebras of type $A \quad 526$

Han Yu, On GILP's group-theoretic approach to Falconer's distance problem $\quad 547$

Steffen Kionke and Clara Löh, A note on $p$-adic simplicial volumes $\quad 563$

Joe Pallister, Linear relations and integrability for cluster algebras from affine quivers $\quad 584$

Mohsen Kian, Mohammad Sal Moslehian and Yuki Seo, Variants of Ando-Hiai type
inequalities for deformed means and applications

Andrea Lucchini, Finite groups with the same join graph as a finite nilpotent group $\quad 640$

Muhammad Fazeel Anwar, Mairaj Bibi and Muhammad Saeed Akram, On solvability of
certain equations of arbitrary length over torsion-free groups

Jim Brown and Huixi Li, Congruence primes for Siegel modular forms of paramodular level and applications to the Bloch-Kato conjecture

Nazife Erkurşun-Özcan and Farrukh Mukhamedov, Spectral conditions for uniform $P$-ergodicities of Markov operators on abstract states spaces

Gabriella D'Este, Derya Keskin Tütüncï and Rachid Tribak, $D 3$-modules versus D4-modules - Applications to quivers

Toru Sasahara, Real hypersurfaces in complex space forms attaining equality in an inequality involving a contact $\delta$-invariant

Filip Misev and Gilberto Spano, Tight fibred knots without L-space surgeries

Daisuke Kishimoto, Akihiro Ohsita and Masahiro Takeda, Note on Samelson products in exceptional Lie groups

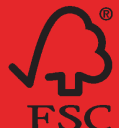

FSC

www.tsc.org
MIX

Paper from responsible sources FSC ${ }^{\odot}$ C007785
CAMBRIDGE UNIVERSITY PRESS 